\title{
Statistics Self-Efficacy and Learning Styles as Predictor of Statistics Anxiety
}

\author{
Ogbogo, Stella, Dr.Amadi, Glory N. \\ Department of Educational Psychology, Guidance and Counselling \\ University of Port Harcourt \\ Department of Educational Psychology, Guidance and Counselling \\ University of Port Harcourt
}

\begin{abstract}
The study investigated statistics self-efficacy and learning styles as predictors of statistics anxiety among graduate students in University of Port Harcourt. Seven research questions and six null hypotheses were formulated to guide the study. The participants in the study were 150 (male $=86$, female 64 ) graduate students drawn through stratified random sampling technique. Three valid instrument titled; statistical anxiety rating scale (STARS), current statistics self-efficacy scale (CSSES), and Grasham Reichann student learning style scales(GRSLSC) was used for data collection. The validity of the instrument was determined using multivariate statistical method of factor analysis. The reliability indices of the instrument were estimated using the Cronbach alpha with coefficients values for statistics anxiety rating scale. 916 and sub scales of $.884 .71, .80, .70, .63, .60$. Current statistics self-efficacy $r=.623$, and $.56,52,53,54,51$, 60 coefficients for the Grasha-Riechmann student learning style scales sub scales. Research question 1, was answered using descriptive statistics of mean and standard deviation, while 2, 3, 4 and 5 was answered using simple and multiple regression. The null hypothesis tested at 0.05 level of significance with ANOVA associated with multiple regression and $\mathrm{t}$ - test associated with simple regression was used for providing answers to the null hypothesis. The result revealed that the statistics anxiety level of graduated student was high, Statistics self-efficacy and learning styles both individual and jointly was seen to predict statistics anxiety. It was recommended that psychological and educational intervention be carried out in the context of increasing statistics self-efficacy and reducing statistics anxiety. Based on findings implications were made and suggestions for further studies.
\end{abstract}

\section{Key word; statistics anxiety, statistics self-efficacy, learning styles}

\section{Introduction}

Decisions taken in the society are made on the basis of statistics (Joe, 2005). The problem of finding trust worthy results lies in understanding how data are collected, analyzed and reported and if data are confounded, so are results (Earp, 2007). Earp further viewing did assert that the general population likely lacks the skill to think critically about the results of statistically complex empirical studies. Therefore Possessing good statistical skill is essential in making informed decision as the government, economy, education, and health care system are all dependent in part upon the statistical results of scientific studies of which without a clear understanding of the procedure for collecting, reporting and analyzing data, people are misinformed (Earp, 2007, Jordan \& Haines 2003; Schneider, 2004). Being that the society is dependent on statistical studies to make decision, a lot of importance is placed on the acquisition of statistical skill. Thus most graduate or university programmes therefore requires students to complete research methods including statistics courses or a blended combination thereof (Davis 2003; Perepiczka, Chandler \&Becorra, 2011)

Possessing rudimental research knowledge is of extreme necessity for post graduate students in a research university where the production of a well written thesis is one of the major requirements of a postgraduate (Masters or Doctoral) conferment Koh\&Zawi (2014). Viewing along the same line, Kpolovie (2010) asserts that conducting of a research is a sine qua non for graduation, be it for first degree, masters or 
doctoral level. Statistics courses are key requirement for many university programmes (McGrath et al, 2015; Onwuegbuzie\& Wilson, 2003; Perepiczka et al 2011). These courses help students learn the skills necessary to conduct their own research to interpret and critically evaluate real world concepts. (Gal, 2002). Research however has shown that not all students are confident on the subject of statistics as there is a widespread emotional reaction evoking a feeling of anxiety both to undergraduate and post graduate students required to take the course (Collins \&Onwuegbuzie. 2007; Onwuegbuzie\& Dally 1999; Onwuegbuzie, 1997, 2004; Koh\&Zawi, 2014).

Research has revealed that a high parentage of post-secondary students perceives statistics as one of the most-stressful, feared, difficult, unpleasant least enjoyed courses in their curricula (Baloglu, 2004; Bell, 2008: Collins \&Onwnegbuzie 2007; Dyleman, 2011; Onwuegbuzie \& Willson, 2003; Pan \& Tang, 2005; Perepiczka et al 2011). Researchers also have found out that the most pervasive behavioural challenges that students face is on performance on statistical analysis on project, thesis, dissertation, homework, assignment quiz and final exams. (Bell, 2008 Onwuegbuzie\&wilson 2003). This feeling of anxiety relating to dealings in statistics is labeled statistics anxiety. It has been defined as any anxiety that results when encountering statistics irrespective of the type of the statistical analysis being carried out (Onwuegbuzie, Daros\&Dynan 1997). It is the apprehension which occurs when individual encounter statistics in any form and at any level (Onwuegbuzie, 2004). While Cruise Cash \& Bolton in Perecpzka (2011) defined it as "the feeling of anxiety encountered when taking statistics course or doing statistical analysis: that is gathering, processing and interpreting" (p. 92). Adding to this definition of statistics anxiety, Zeidrer (1991) stated that this anxiety is accompanied by worry, tension and physiological symptoms of stress when students are faced with taking a statistics class.

It is defined by affective, cognitive, physiological aspects such as worry, intrusive thoughts, mental disorganization and tension when working with statistics (Zeidner 1991). In mild forms it may induce only a feeling of minor discomfort severe forms however can result in negative outcomes. Such as apprehension, fear, nervousness and panic (Onwuegbuzie et al 1997; Onwuegbuzie 2004). Statistics anxiety is situationspecific in as much as the symptom only emerge at a particular time and in a particular situation specifically when learning or applying statistics in a formal setting and affects students learning or applying statistical principles, methods, manipulations and formula (Onwuegbuzie 2004; Zeidner 1991).). Statistics anxiety primarily affects a student's ability to understand fully research articles as well as to analyze and interpret statistics. Onwuegbuzie, (1995; 1997). Statistics anxiety is related to statistics test anxiety, statistics content anxiety, individual's history of success and failure, experiences in situation involving maths, personal background; ethnicity, social class and gender, prior educational experience, learning motivation, personality, low degree of academic self confidence in general, perceived low probability of success in statistics, test and class anxiety, fear of asking for help, motivation for learning, statistics self-efficacy, learning styles, computational self-concept. (Earp, 2007; Eagly\&Chakin, 1992; Finney \&Schraw, 2003; Onwugbuzie\& Wilson, 2003; Rodarte-Iuna\& Sherry 2008; Walsh \&Ngumba-Agwunobi, 2002; Vashedi, Farrokhi, Gahramani and Ali, 2012; Zeidrer, 1991).

Lane, Hall \& Lane (2004) has viewed thatstatistics self-efficacyis a concept closely related to statistics anxiety. Several researchers have found that self-efficacy is a good predictor of performance, efforts, persistence and future enrollment in courses within a specific domain (Devonport, lane, Milton \& Williams, 2003; Pajares\&Kranzler, 1995). In Gross (2010), Bandura 1977 refers to self-efficacy as our own belief that we can act effectively and exercise some control over events that influence our lives. While Schneider (2011) Saw self-efficacy as person's level of confidence in his ability to perform specific tasks under specific conditions or situations - in relation to self-efficacy it is an individual's confidence in their ability to complete specific statistics related task Schneider, (2011). Finney \&Schraw, (2003) view that selfefficacy to learn statistics is an individual's confidence in his or her ability to successfully learn statistical skills necessary in a statistical course. They further viewed that students who have high level of anxiety have also been found to rate their own statistical self-efficacy as low which can impact one's ability to learn statistical concept and excel in these courses. According to Unram\& Beck, (2004), self-efficacy belief plays a major role in a student's confidence in the ability to complete advanced research. While Onwuegbuzie (2003) states that students expectation of their performance are an important manifestation of the levels of self-efficacy

A concept related to this is learning style. Learning style refers to how learners gather, sift through, interpret, organize and come to conclusion about and store information for further use. (Chick, 2016). 
According to Cassidy, (2004) it is the application within a learning situation of an individual's typical mode of problem solving, thinking perceiving and remembering. It is the style which helps learner to process information, (Baneshi, Karamdoust \& Hakimzadeh, 2013). Learning style is an ability learning that portrays student's capability to gain knowledge through learning process (Grasha, 1996). It refers to the preferential way in which students absorb, processes comprehend and retain information. The fundamental idea behind learning style is that each one has a specific preference and we learn best when information is presented to us in this style. Bias \& Carthal (1999) revealed that different learning styles are adopted by students. Grasha \& Reichmann in Baykul et al (2010) identified six types of learning styles: the ones who learn on their own (independent), the ones who are dependent on their teacher and others in learning (dependent), the ones who cooperate with others (collaborative), the one who compete with others (competitive), the ones who take part in activities (participative), and the ones who are shy and uninterested in learning (avoidant). Learning styles adopted by students have an influence on their academic achievement and also can predict academic achievement (Cano, 1999; Felder and Brent, 2005; Sahoo \& Chance 2013; Orshun, 2006).

To investigate graduate students experiences in statistics courses and research method many researchers have undertaken and studied various variables relating to statistics anxiety such include motivation for further learning, finny \&schraw, (2003), statistics self-efficacy Onwugbuzie\&Willson (2003), Onwuegbuzie (2004), found that procrastination significantly relates to statistic anxiety, Walsh \& UgumbaAgwunobi (2010) studying evaluation concern, fear of failure and perfectionism reported these variables as provoking statistics anxiety, Perepiczka et al (2011) studying relationship between graduate students statistics self-efficacy, statistic anxiety and social support found a negative correlation between statistics self-efficacy and statistics anxiety. Willams, (2010) studying statistics anxiety and instructor immediacy found that this both were significantly related.

The purpose of this study is therefore to examine some of the various factors that have not been investigated that have been introduced in previous research in one study. The aim is to determine how statistics anxiety is predicted by statistics self-efficacy and learning styles.

The following research questions guided the study.

1. What is the statistics anxiety level of graduate students?

2. To what extent does statistics self-efficacy predict statistics anxiety?

3. To what extent does learning styles (independent, avoidant, collaborative, dependent, competitive and participants) independently predict statistics anxiety?

4. To what extent does learning styles (independent, avoidant, collaborative, dependent, competitive and participant) jointly predict learning style?

5. To what extent does statistics self-efficacy and learning styles jointly predict statistics self-efficacy? At .05 level of significance the following null hypothesis were tested Statistics self-efficacy does not significantly predict statistics anxiety

6. Learning styles (independent, avoidant, collaborative, dependent, competitive and participant) independently does not significantly predict statistics anxiety.

7. Learning styles (independent, avoidant, collaborative, dependent, competitive and participant) jointly does not significantly predict statistics anxiety.

8. Statistics self-efficacy and learning style jointly does not significantly predict statistics anxiety.

\section{Method}

This study employed a correlational research design. Correlational design is used in a situation where the researcher seeks to establish the relationship between two or more variables (Nwankwo, 2006). Employed within this design is the Multiple prediction design to see the prediction of statistics self-efficacy and learning styles on statistics anxiety. Multiple prediction design is a high order correlational research design that extents the least-squares association principle to the study of relationship between one dependent variable and two or more independent variables. (Kpolovie, 2010). The population of this study consisted of all the post graduate students of University of Port Harcourt admission for the 2014/2015 academic sessions for master's programme which was 2250 . The sample size of the study was 150 (88 males 62 female) post graduate students of University of Port Harcourt. The sampling technique was stratified random technique where the population was stratified based on gender. The instrumentation for this research consisted of one statistics anxiety statistics, one self-efficacy measure and one learning style measure; all of the instrument were combined into one package (instrument packet). 
The instruments are: Statistical Anxiety Rating Scale (STARS) developed by Cruise and Wilkins (1980) was adapted for the study to measure the independent variable statistics anxiety. It is designed to assess student levels of statistical anxiety. It has six factors which are worth of statistics, interpretation anxiety, class anxiety, computational self-concept and fear of asking for help. The instrument is a 51-item Likert scale ranging from $1=$ no anxiety to $5=$ very much anxiety and measures anxiety in two parts. The first part includes 23 statements related to statistics anxiety and the second part has 28 items related to respondent's feeling and dealing towards statistics. The items response format was modified and was also measured on a 5-point Likert-format scale that ranged from $1=$ completelyagreeto $5=$ strongly disagree. A high score on each of the six subscales represents high anxiety in that area. Cronbach alpha Reliability for each of the subscales was reported to range between .68 to .94 with a median of .88 (Worth of Statistics .94, Interpretation Anxiety .87, Test and Class Anxiety .69, Computational Self-Concept .88, Fear of Asking for Help .89, and Fear of Statistics Teachers .80). Validity evidence of factor analysis was conducted in establishing validity. Cronbach alpha was used to establish reliability for this study which ranged from .60 to 84 for the six subscales with Worth of Statistics .84, Interpretation Anxiety .71, Test and Class Anxiety .80, Computational Self-Concept .70, Fear of Asking for Help .63, and Fear of Statistics Teachers .60. and reliability for the whole instrument was .916 .

The Current statistics self-efficacy scale (CSSES) developed by finny \& Schraw (2003) was adapted to assess student's confidence in their ability to solve specific statistics related task. It was used in measuring the independent variable statistics self-efficacy. It has 14 item, each item in the CSSES was scored on a Likert type scale ranging from 1 (no confidence all) to 6 (complete confidence) scores ranged from 14 (low level of statistical self-efficacy) to 84 (high level of statistical self-efficacy). The scale has strong internal consistency $(\alpha=.93)$ and the factor analysis revealed a unidimensional solution and all factors meeting the inclusion criteria with the lowest coefficient at .55 (Finney \&Schraw, 2003). Within the current data set, the reliability index using Cronbach alpha was .62.

The Grasha-Reichmann learning style scale developed by Grasham and Reichan (1996) was used in assessing the independent variable of learning styles. It is a 60 item scale measuring 10 different learning styles of independent, avoidant, competitive, collaborative, participant and dependent. The scoring pattern was modified to the form of a 5 point Likert scale of 1 completely agree to 5 completely disagree Cronbach alpha reliability for the six subscales is reported to be .50 dependent, .68 competitive, .55 independent, .81 avoidant, .77 participant and .77 for cooperative. Using Cronbach alpha, reliability within this study was found to be .75 for the whole instrument while the subscale of independent was ,56, avoidant .52, collaborative .53 , dependent .54 , competitive .51 and participant .60 . Data was analyzed using mean, standard deviation, t-test, simple and multiple regression, and ANOVA associated with multiple regression.

\section{Result}

Research Question 1: What is the statistics anxiety level of graduate students?

Table 1.1: Mean and standard deviation analysis showing the statistics anxiety level of graduate students

\begin{tabular}{|l|l|l|l|l|l|l|l|}
\hline & N & $\begin{array}{l}\text { Mini } \\
\text { stat }\end{array}$ & Max. Sta & Sum Stg & Mean & Std. Error & Std. Dev \\
\hline Statistic & 150 & 103.00 & 224.00 & 22985.00 & 153.23 & 1.958 & 23.991 \\
\hline Anxiety & & & & & & & \\
\hline
\end{tabular}

The table 1.1 shows the mean score of 153.23 and standard deviation of 23.99 this implies that the statistic anxiety level of graduate student is high. This is based on the fact that the mean of 153.23 is above the criterion mean point mean of 130

Research Question 2: To what extent does statistics self-efficacy predict statistics anxiety?

Hypothesis 1: Statistics self-efficacy does not significantly predict statistics anxiety.

Table 1.2: Showing regression analysis of the prediction of statistics self-efficacy on statistics anxiety.

\begin{tabular}{|l|l|l|l|l|}
\hline Model & $\mathrm{R}$ & $\mathrm{R}$ square & Adjusted $\mathrm{R}^{2}$ & Std. Error of the estimate \\
\hline 1 & .163 & .026 & 0.20 & 11.36. \\
\hline
\end{tabular}


Table 1.2: Shows that $\mathrm{R}$ is .163 which indicates a positive relationship between statistics self-efficacy and statistics anxiety that is statistics self-efficacy predicts statistics anxiety. The coefficient of determination $\mathrm{R}^{2}$, $\mathrm{R}$ square is .026 showing that the proportion of variance in statistics anxiety can be explained by statistics self-efficacy. This implies that $26 \%$ of the variation in statistics anxiety can be accounted for by statistics self-efficacy.

Table 1:3 $\mathrm{t}$ - test associated with multiple regression showing the prediction of statistics self-efficacy on statistics anxiety.

\begin{tabular}{|c|c|c|c|c|c|c|}
\hline \multicolumn{2}{|c|}{ Model } & \multicolumn{2}{|c|}{ Unstandardized Coefficients } & \multirow{2}{*}{$\begin{array}{c}\text { Standardized } \\
\text { Coefficients } \\
\text { Beta }\end{array}$} & \multirow[t]{2}{*}{$\mathrm{T}$} & \multirow[t]{2}{*}{ Sig. } \\
\hline & & B & Std. Error & & & \\
\hline \multirow[t]{2}{*}{1} & (Constant) & 141.021 & 6.396 & & 22.649 & .000 \\
\hline & $\begin{array}{l}\text { Statistics self- } \\
\text { effi }\end{array}$ & .248 & .124 & .163 & 2.004 & .047 \\
\hline
\end{tabular}

a. Dependent Variable: statistics anxiety

b. Predictor variable; statistics self-efficacy

Table 1.3: the table shows Beta value $=.163$ and $\mathrm{t}=2.004(\mathrm{~B}=.163, \mathrm{t}=2.004 ; \mathrm{P}<0.05)$. The null hypothesis is rejected and this shows that statistics self-efficacy significantly predicts statistics anxiety.

Research Question 3: To what extent does learning styles (independent, avoidant, collaborative, dependent, competitive and participant) independently predict statistics anxiety?

Hypothesis 2: Learning styles (independent, avoidant, collaborative, dependent, competitive and participant) independently does not significantly predict statistics anxiety.

Table 1.4: Multiple regression showing the prediction of learning styles (independen, avoidant, collaborative, dependent, competitive and participant) on statistics anxiety.

\begin{tabular}{|l|l|l|l|c|}
\hline Model & $\mathrm{R}$ & $\mathrm{R}$ square & Adjusted $\mathrm{R}^{2}$ & Std. Error of the estimate \\
\hline 1 & $461^{\mathrm{a}}$ & .212 & .179 & 21.737 \\
\hline
\end{tabular}

The table shows a multiple regression $(\mathrm{R})$ value of .461, regression squared $\left(\mathrm{R}^{2}\right)$ of .212 ; Adjusted $\mathrm{R}$ square .179 and standard error of estimate 21.737 change statistics in this table shows $\mathrm{R}^{2}$ change of .212 which means that learning style of independent, avoidant, collaborative, dependent, competitive and participant as predictors accounts for $21 \%$ of the proportion of variance in statistics anxiety.

In order to test the hypothesis, $\mathrm{t}$ - test associated with multiple regression was employed.

Table 1.5: $\quad t$ - test analysis associated with multiple regression showing the relative contribution of each learning style (independent, avoidant, collaborative, dependent, competitive and participant).

\begin{tabular}{|c|c|c|c|c|c|}
\hline \multirow[t]{2}{*}{ Model } & \multicolumn{2}{|c|}{$\begin{array}{l}\text { Unstandardized } \\
\text { Coefficients }\end{array}$} & \multirow{2}{*}{$\begin{array}{l}\text { Standardized } \\
\text { Coefficients } \\
\text { Beta }\end{array}$} & \multirow[b]{2}{*}{$\mathrm{t}$} & \multirow[b]{2}{*}{ Sig } \\
\hline & B & $\begin{array}{l}\text { Std. } \\
\text { Error }\end{array}$ & & & \\
\hline $\begin{array}{l}\text { Constant } \\
\text { Independent } \\
\text { Avoidant } \\
\text { Collaborative } \\
\text { Dependent } \\
\text { Competitive } \\
\text { Participant }\end{array}$ & $\begin{array}{l}100.428 \\
.716 \\
1.181 \\
.090 \\
.611 \\
-190 \\
-426\end{array}$ & $\begin{array}{l}10.240 \\
: 376 \\
.270 \\
.364 \\
.413 \\
.316 \\
.371\end{array}$ & $\begin{array}{l}.195 \\
.378 \\
.028 \\
.171 \\
-054 \\
-.136\end{array}$ & $\begin{array}{l}9.807 \\
1.907 \\
4.371 \\
.248 \\
1.478 \\
-608 \\
-1.148\end{array}$ & $\begin{array}{l}000 \\
.059 \\
.000 \\
.805 \\
.142 \\
.548 \\
.253\end{array}$ \\
\hline
\end{tabular}

As shown in table 1:5 the beta value for learning styles are independent -.195, Avoidant .379, collaborative $=-.028$, dependent $=.171$, competitive $=.-.054$ and participant $=-.136$. This shows that 
learning style of avoidant has the highest or is most independent predictor of statistics anxiety followed by independent then dependent, participant, competitive and the least predictor collaborative.

Again the table revealed the computed t-test value associated with multiple regression of the independent contribution of learning styles. For independent $\mathrm{B}=.195, \mathrm{t}=1.907 \mathrm{P} .059>.05$ (not significant), for avoidant $\mathrm{B}=.378, \mathrm{t}=4.371 \mathrm{P} 000<.05$ (significant), for collaborative $\mathrm{B}=-.028 ; \mathrm{t}=-248$ $\mathrm{P} .805>0.5$ (not significant), dependent $\mathrm{B}=.171, \mathrm{t}=1.472 \mathrm{P} .142>0.5$ (not significant) competitive $\mathrm{B}=-$ $.054 \mathrm{t}=-602 \mathrm{P} .548>.05$ (not significant) and participant $\mathrm{B}=-.136, \mathrm{t}=1.148 \mathrm{P} .253>.05$ (not significant). This result shows that avoidant learning style significantly predicts social phobia while independent, dependent, collaborative, competitive, participant, does not significantly predict statistics anxiety..

Research Question 4: To what extent does learning style (independent, avoidant, collaborative, dependent, competitive and participant) jointly predict statistics anxiety?

Hypothesis 3: Learning styles (independent, avoidant, collaborative, dependent, competitive and participant jointly do not significantly predict statistics anxiety.

TABLE 1.6: ANOVA associated with multiple regression analysis showing the joint prediction of learning styles (independent, avoidant, collaborative, dependent, competitive and participant) on statistics anxiety.

\begin{tabular}{|l|l|l|l|l|l|}
\hline Model & Sums of square & Df & Mean square & F & Sig \\
\hline Regression & 18188.300 & 6 & 3031.383 & 6.419 & 0.00 \\
\hline Residual & 67568.53 & 143 & 472.507 & & \\
\hline Total & 85756.833 & 149 & & & \\
\hline
\end{tabular}

a. Dependent variable; statistics anxiety

b. Predictor; c. constant) participant, avoidant, competitive, independent, collaborative, dependent.

ANOVA associated with multiple regression as shown in table 6.1 reveals that $\mathrm{F}$ - value $(6,143)=6.4119$. $\mathrm{P}$ $<.05$ therefore the null hypothesis that learning styles (independent, avoidant, competitive dependent, collaborative and participant) jointly significantly does not predict statistics anxiety is rejected.

Research Question 5: To what extent does statistics self-efficacy and learning styles jointly predict statistics self-efficacy?

Hypothesis 4: Statistics self-efficacy and learning styles do not significantly predict statistics anxiety.

Table 1.7: Multiple regression showing the joint prediction of statistics self-efficacy and learning styles on statistics anxiety.

\begin{tabular}{|l|l|l|l|l|}
\hline Model & $\mathrm{R}$ & R square & Adjusted $^{2}$ & Std. Error of the estimate \\
\hline 1 & $341^{\mathrm{a}}$ & .116 & .104 & 22.70412 \\
\hline
\end{tabular}

The Regression co-efficient $\mathrm{R}=.341, \mathrm{R}$ square $=.116$, adjusted $\mathrm{R}$ square $=.104$ and std. Error is seen to be 22.70412 . This implies that only $11 \%$ the proportion of variation in statistics anxiety can be explained or accounted for by the joint prediction of statistics self-efficacy and learning styles that is learning styles and statistics self-efficacy accounts for only $11 \%$ of the variation in statistics anxiety.

Table 1.8: ANOVA associated with Multiple regression showing the joint prediction of statistics selfefficacy and learning styles on statistics anxiety.

\begin{tabular}{|l|l|l|l|l|l|}
\hline Model & Sum of square & Df & Mean square & F & Sig \\
\hline Regression & 9981.733 & 2 & 4990.866 & 9.682 & 000 \\
\hline Residual & 75775.101 & 147 & 515.477 & & \\
\hline Total & 85756.833 & 149 & & & \\
\hline
\end{tabular}

a. Dependent variable; statistics anxiety

b. Predictor; (constant) learning style, statistics self-efficacy

Table 7.2: Shows an F - value of $9.682 \mathrm{df}=(147) \mathrm{P}<.05$. The null hypothesis thus of statistics selfefficacy and learning styles not significantly predicting statistics anxiety is rejected. This implies that statistics self-efficacy and learning styles significantly predicts statistics anxiety.

\section{Discussion and Conclusion}

This study focused on the prediction of statistics self-efficacy and learning styles on statistics anxiety. The finding of this study reveals that the statistics anxiety of graduate students is high as the mean score of 153.33 is high and above the criterion mean. This finding is consistent with Onwuegbuzie and Willson (2003) findings where study revealed that $80 \%$ of graduate students' experiences statistics anxiety. 
Liu, Onwuegbuzie\&Meng (2012) using samples size of 201 college students in china found that students experiences statistics anxiety this is also consistent with the findings of Perepiczka et al (2011).

The finding of the present study shows that statistics self -efficacy significantly predicts statistics anxiety from table 4:1 and 4:2 $\mathrm{P}<.05$ when data was analyzed using multiple regression. Coefficient of determination shows that only $26 \%$ of the variation in the proportion of statistics anxiety can be accounted for by the prediction of statistics self-efficacy. The finding of Finney and Schraw (2003) shows a moderate negative relationship between one's current statistical self-efficacy and statistics anxiety whereby those with lower self-efficacy also had a higher rating of anxiety. In the same vein, Schneider (2011) also found a low to moderate inverse relationship with statistics anxiety and statistics self-efficacy and this supports past findings (Onwuegbuzie, 2000; Pajares\& Miller 1995; Perepiczka et al 2011) and it has been suggested that poor self-efficacy beliefs in the face of learning statistics may create a self-fulfilling prophecy for students.

Table 1.5 and 1.6 revealed that learning style predicts for $21 \%$ for the proportion of variation in statistics anxiety as seen by the coefficient of determination. The learning style of avoidant significantly predicted more statistics anxiety as $\mathrm{P}<0.5$ while independent, collaborative, participant, competitive, and dependent learning styles did not significantly predict statistics anxiety table 6.1 shows that learning styles significantly predicts statistics anxiety as $\mathrm{F}(6,143)=6.419 \mathrm{P}<05$. There is a significant joint prediction of learning styles on statistics anxiety. Learning styles adopted by students thus can predict their having anxiety in statistical courses though findings by Vashed et al (2012) in a study of 246 undergraduates in Iran found that learning strategies factors was negatively associated with statistics anxiety. The divergent finding could be accounted for by difference in the population of study as it used undergraduate students while this study used post graduate students.

Finding by Kinkead (2015) indicated that collaboration reduces stress and improves course performance. Bell (2008) reveals that highly anxious students learn complex statistical procedures when in group and this is supported by Davis (2003) who viewed that collaboration significantly reduces statistics anxiety. Research findings has shown that a high percentage of students benefit from collaborative environment and that classroom environment where students Participate, interact and collaborate improves performance amongst a variety of students and also mitigate statistics anxiety level among some students (Brindley, Walti\&Blachke, 2009: Chen, Gonyea\&Kuh 2008; Delucchi, 2006, 2007; Harrigton\&Schibik 2004; Keeler \&Steinhorst 1995; Mesh 2010; Potthast, 1999).

Table 7.1 shows the joint prediction of statistics self-efficacy and learning style on statistics anxiety which was significant as $\mathrm{P}<.05$. Thus statistics self-efficacy and learning style significantly predict statistics anxiety.

Based on the finding of the study, it is concluded that graduate students have high statistics anxiety. Statistics self-efficacy significantly predicts statistics anxiety, learning styles significantly predicts statistics anxiety with avoidant learning style significantly predicting it. Learning styles and statistics self-efficacy jointly significantly predicts statistics anxiety.

It is important to continue to address the issue of statistics anxiety as studies have revealed that it a prevalent cases amongst graduate students teachers and professors statistics can play key role in positively impacting their students towards appreciating the usefulness of statistics in their professions by developing and teaching statistics courses in a way that will be sensitive to student learning styles, and to create an atmosphere during statistics courses where students can experience their less dominant learning style in a non threatening environment as well as making themselves available and accessible to students. Students completing a learning style instrument early in classes so that they can be aware of their learning styles and teachers adopting different approach to teaching statistical courses can mitigate anxiety. Psychological and educational interventions can be carried out in the context of increasing statistics self-efficacy and reducing statistics anxiety.

Findings from this study will increase knowledge on statistics anxiety, statistics self-efficacy, learning style. It documents student experiences which can serve as a plat form for conducting further research on this area, implement interventions aimed at increasing success in statistics courses, reducing statistics anxiety, increasing statistics self-efficacy. It equips students and teacher to know learning styles and also help prepare students for challenges.

Limitation of this study was that a more diverse sample was not sampled. However, a representative sample was obtained. Time constraint burden was put on the students to respond to as there were three scales for the participants to respond to. 
It is suggested that broader demographic variables be used and experimental studies be carried out to view the effectiveness of the various intervention that can help mitigate statistics anxiety and increase statistics self-efficacy.

\section{References}

[1] Abd-El-Fattah, S.M. (2005). The effect of prior experience with computers, statistical self efficacy and computer anxiety on students' achievement in an introducing statistics course: A partial least squares path analysis international education journal, vol. 5(5), 71-79.

[2] Baykul, Y., Gürsel, M., Sulak, H., Ertekin, E., Yazıc1, E., Dülger, O., Aslan, Y., \&Büyükkarc1, K. (2010) A Validity and Reliability Study of Grasha-Riechmann Student Learning Style Scale. International Journal of Social, Behavioral, Educational, Economic, Business and Industrial Engineering, 4(3), 323-2330

[3] Baloglu, M. (2004).Statistics Anxiety.Some interesting differences.Educational research quarterly, 27(3), 3848 http://erguarlerly.org/

[4] Bell, J.A. (2008). Statistics anxiety and Business statistics: the internationalstudent education, 12(2), 282-286.

[5] Brindley, J.E., Walti, C., \&Blacke, L.M. (2009).Creating effective collaborative learning groups in an online environment.The international review of research in open and distant learning, 10(3), 1-10.Retried from www.irrod/.org.

[6] Cano, J. (1999). The relationship between learning style, academic major and academic performance of college students.Journal of agricultural education, 40(1), 30-37.

[7] Collin, K.M., \&Onwuegbuzie, A.J. (2007). I cannot read my statistics textbook: the relationship between reading ability and statistics anxiety. The journal of Negro. Education, 76(2), 118-129. retrieval from http://www.journalnegroed.ord/.

[8] Chen, P.D., Gonyea, R. \&Kuh, G. (2008) Learning at a distance; engaged or not? Innovate, 4(3), 1-10. Retrieved form www.irrodi.org/index.php/irrodl.

[9] Choi, N. (2005). Self-efficacy and self concept as predictors of college student's academic performance: Psychology in the schools, 42,192-205. http://dx.do1,org/10.1002/pits. 20048.

[10] Devenport, T.O., Lane, A.M., Mitton.,\& Williams (2003). Self-efficacy as a predictor of strategy used to cope with dissertation stress. Paper presented at the annual conference of the British psychological society, Bournemouth, UK.

[11] Delucchi, M. (2006). The efficacy of collaborative learning groups in an undergraduate statistics course. College teaching, 54(2), 244-248.doi.10.32001CTCH.54.2.244-248.

[12] Delucchi, M. (2007).Assessing the impact of group projects on examination performance in social statistics.Teaching in higher education, 12(4), 447-460.doi:10.1080/13562570701415383.

[13] Davis, S. (2003). Statistics anxiety among female African American graduate level social work students.Journal of teachingin socialwork, 23(314), 143-158.doi:10-1300, 1067v23no3_12.

[14] Diaz, D.P. \&Cartnal, R.B. (1999).Company student learning styles in an online Distance learning class and an environment on campus class. College Teaching, 47 (4), 130-135.

[15] Earp, S.M. (2007). Development and validation of the statistics anxiety measure (unpublished Doctorate Dissertation). The University of Denver, college of education.

[16] Gal, I. (2002). Adults statistical literacy: meaning, components, responsibilities. International statistical review, 70 1-51, http://dx.doi.org/10-1111/j.1751-5823.2002.tb00336.x

[17] Finney, S.J., \&Schraw, G. (2003).Self-efficacy beliefs in college statistics courses.Contemporary educational psychology. 28, 161-186. http://dx:do1 org/10.1016/50361-476x(02)0015-2.

[18] Harrington, C.F. \&Schibik, T.J. (2004).Method for maximizing engagement in the introductory business statistics course.A review.The journal of American Academy of Business, Cambridge, 4(1), 360-364.Retrieved form http://www.jaabc.com/brc/html.

[19] Joe A.I. (2005). Fundamental Statistics for Education and the Behaviour Sciences: Ibadan; Kraft Books Limited.

[20] Kinkead, K.J. (2015). A qualitative assessment: adult perceptions of collaboration as mitigation for statistics anxiety unpublished dissertation Walden University.

[21] Keeler, M.C., \&Sternhorst, R.K. (1995). Using small groups to promote active learning in the introducing statistics course; A report from the field. Journal of statistics education. 3(2), Retrieved form http://www.amstat.org./publications/jse.

[22] Koh, D., \&Zawi, M.K. (2014).Statistics anxiety amongst post graduate students.International education studies 7(13), 166-176. http://dx.do1org/10.5539/ies.v7n/3p166.

[23] Lane, A.M., Hall, R., \& Lane (2004). Self-efficacy and statistics performance among sport studies student. Teaching in higher education, 9, 435-448. 
[24] Liu, S., Onwuegbuzie, A.J., \&Meng L. (2011).Examiniation of the score reliability and validity of the statistics anxiety rating scale in a Chinese population; comparisons of statistics anxiety between Chinese college students and their western counterparts.Journal of educational enquiring, 11(1), 29-42.Retrieved form www.ojs.unisa.edu.arlindex.php/EDEQ.

[25] McGrath, A.L., Ferns, L., Wanamaker, K., \& Brown, S. (2015). Reducing Anxiety and increasing selfefficacy within an advanced graduate. The Canadian journal for the scholarship of teaching and learning. 6(1), 1-17. http://dx:dol.org/10.1080/1356251042000252372.

[26] Mesh, L.J. (2010). Collaborative language learning for professional adults.Electronic journal of e-learning, 8(2), 161-172.Retrieved formwww.ejel.org.

[27] Nwankwo, O.C. (2005). A Practical Guide to Research Writing.Port Harcourt; Pam unique publishers.

[28] Onwuegbuzie, A.J, \& Daley, C.E. (1999).Perfectionism and statistics anxiety.Personality and individual differences, 26, 1089-1102.

[29] $\quad$ http://dx.doi:org/10.1011.

[30] Onwuegbuzie, A.J., Daros, D., \& Ryan J. (1997). The components of statistics anxiety: A phenomenological study. Focus on learning problems in mathematics, 19(4),11-35

[31] Onwuegbuzie, A.J., \& Wilson, V.A. (2003) Statistics anxiety; Nature, etiology, antecedents, effects and treatments - a comprehensive review of the literature.Teaching in higher education, 8,195-209.

[32] http.//dx.doi.org/10.1080/1356251632006052447

[33] Onwuegbuzie, A.J. (2004). Academic procrastination and statistics anxiety.Assessment \& Evaluation in higher education, 29(1), 1-19.

[34] Orhun, O. (2006). The relationship between learning styles and achievement in physics and calculus courses. Retried form http://math.unipa.it/-igrim/21 project/2/charlolte orhun $0 \% 20$ paper edite.pdf.

[35] Pajares, F., \& Miller, M.D (1995).Mathematics.Self-efficacy beliefs and general mental ability in mathematical problem solving.Contemporary educational psychology, 42,190198.http://dx:doiorg/10.1037/0022-067.42.2190.

[36] Pan, W. \& Tang, W. (2005).Student's perceptions on factors of statistics anxiety and instructional strategies.Journal of instructional psychology, 32(3), 205-214.

[37] Perepiczka, M., Chandler, N., \& Becerra, M. (2011).Relationship between graduate student's statistics selfefficacy, statistics anxiety, attitude towards statistics and social support.The professional counselor,1(2), 99108. do1:10.15241/mpa:12.99 http//tpcjournal.nbcc.org.

[38] Potthast, M.J. (1999). Outcomes of using small group co-operative learning experiences in introductory statistic courses - College student journal, 33(1), 34-44.Retrieved from http://www.guestia.com/library.

[39] Schneider, W.R. (2011). The relationship between statistics self-efficacy, statistics anxiety and performance in an introductory graduate statistics course.Unpublished Doctoral Dissertation University of South Florida.

[40] Vahedi, S., Farrokhi, F., Issazadegan (2012). The relationship between procrastination, learning strategies and statistics anxiety among Iranian college students: A canonical correlation analysis Iran J. Psychiatry and Bahave Sci. 6(1) 40-46.

[41] Williams, A., S. (2010) Statistics anxiety and instructor immediacy. Journal of statistics education. 18 (2) 118.

[42] Zeidner, M. (1991) Statistics and mathematics anxiety in social science students: some interesting parallels. British journal of educational psychology, 61(1); 319-328,do1:10.1111/j.2044-8279.1991.tb00989.x 